\title{
Failure Mechanism of the Qianjiangping Slope in Three Gorges Reservoir Area, China
}

\author{
Zhenhua Zhang $\mathbb{D}^{1,2}$ Mingming Qian $\mathbb{D}^{1,},{ }^{1,3}$ Song Wei, ${ }^{1}$ and Juxiang Chen ${ }^{1}$ \\ ${ }^{1}$ School of Civil Engineering, Hefei University of Technology, Hefei, Anhui 230009, China \\ ${ }^{2}$ Collaborative Innovation Center for Geo-Hazards and Eco-Environment in Three Gorges Area, Yichang, Hubei 443002, China \\ ${ }^{3}$ State Key Laboratory of Geomechanics and Geotechnical Engineering, Institute of Rock and Soil Mechanics, Chinese Academy \\ of Sciences, Wuhan, Hubei 430071, China
}

Correspondence should be addressed to Mingming Qian; mingmqian@163.com

Received 30 June 2017; Revised 27 November 2017; Accepted 10 July 2018; Published 6 August 2018

Academic Editor: Stefano Lo Russo

Copyright $\odot 2018$ Zhenhua Zhang et al. This is an open access article distributed under the Creative Commons Attribution License, which permits unrestricted use, distribution, and reproduction in any medium, provided the original work is properly cited.

\begin{abstract}
The Qianjiangping landslide is the first large-scale rock slide in Three Gorges Reservoir (TGR) Area, China, after the impoundment of the TGR. Previous studies on the slope showed that most researchers agreed that reservoir impoundment and rainfall were the two main triggering factors of the slope failure. However, there were different views about the influence degrees of the two factors on the slope failure. In order to clarify the influence degrees of each of three conditions (reservoir impoundment, rainfall, and combined effect of reservoir impoundment and rainfall) on the failure of the Qianjiangping slope and reveal the failure mechanism of the slope, underground water tables and stresses in the slope were calculated under the three conditions, respectively, based on fluid-solid coupling theory using the Abaqus software in this paper; then, the failure approach index (FAI) was adopted to analyze the failure characteristics of the slope under each of the three conditions. Research results show that the influence degree of rainfall is greater than that of reservoir impoundment on the slope failure, and the influence degree of the combined effect of reservoir impoundment and rainfall is greater than that of rainfall; the sliding surface runs through only in the condition of the combined effect of reservoir impoundment and rainfall. Study results suggest that with the reservoir water level rising, the toe of the slope was gradually submerged in reservoir water and the strength of rock mass submerged by reservoir water decreased due to water-rock interaction; furthermore, the heavy rainfall was rapidly injected into the slope through the interlayer staggered zone and slope surface, the groundwater table in the middle part of the slope rose rapidly, the sliding force of the slope increased, and the stress concentration appeared at the lower part of the slope; finally, the rock bridges submerged by reservoir water in the front of the slope fractured, and the failure of the slope occurred.
\end{abstract}

\section{Introduction}

The Three Gorges Project (TGP) in China is the largest hydropower project in the world. The first-stage impoundment of the Three Gorges Reservoir (TGR) started on June 1, 2003. After the reservoir water level rose to $135 \mathrm{~m}$ on June 10,2003 , many bank slopes began to deform and some landslides happened [1]. The Qianjiangping landslide occurred on July 13,2003, is the first large-scale rock slide after the first-stage impoundment of the TGR. The landslide is located in Shazhenxi Town, Zigui County, Hubei Province, on the left bank of the Qinggan River, a branch of the Yangtze River
(Figure 1). It is about $4 \mathrm{~km}$ away from the estuary of Qinggan River and about $50 \mathrm{~km}$ away from the Three Gorges Dam. The highest wave generated by the landslide was $39 \mathrm{~m} \mathrm{[2]}$. The catastrophic landslide with a volume of 15 million $\mathrm{m}^{3}$ took 14 people's lives away directly, destroyed 4 factories, 346 houses, and 70 ha of farmland, and made 1200 people homeless. The direct economic loss caused by the landslide was about $\$ 7$ million at that time $[1,3]$.

About the influence of reservoir impoundment and rainfall on the Qianjiangping landslide, many researches were performed by scholars around the world with the methods of field investigation, geological analysis, numerical 


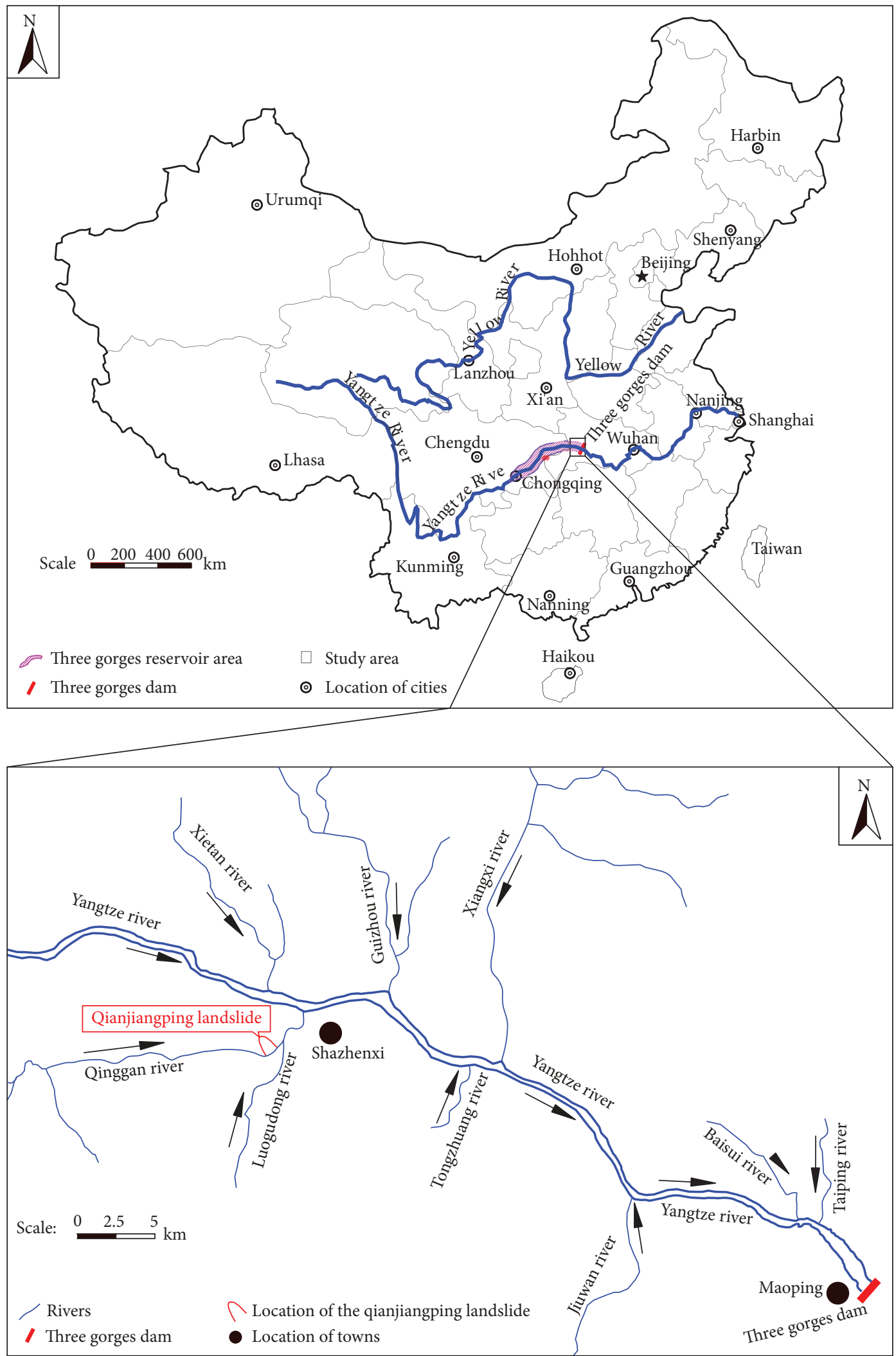

FIgURE 1: Location of the Qianjiangping landslide.

simulation, model test, and so on [1-13]. Although a great deal of research has been done, there are still three different perspectives: (1) the occurrence of the landslide was the result of the combined effect of reservoir impoundment and rainfall [1-7], (2) the influence of reservoir impoundment on the slope stability was greater than that 
of rainfall [8-10], and (3) the influence of rainfall on the slope stability was greater than that of reservoir impoundment $[11,12]$. The root of the different above-mentioned viewpoints is that the scholars do not effectively distinguish and quantize the influence degrees of reservoir impoundment and rainfall on the slope failure. In order to study clearly the different contributions of reservoir impoundment and rainfall to the failure of the Qianjiangping slope and reveal the failure mechanism of the slope, a numerical simulation based on fluid-solid coupling theory was carried out and the groundwater tables and stress fields of the slope under the three conditions (reservoir impoundment, rainfall, and combined effect of reservoir impoundment and rainfall) were obtained; the failure approach index (FAI) was adopted to analyze the influence degrees of each of the three conditions on the slope failure in this paper.

\section{Overview of the Qianjiangping Landslide}

The Qianjiangping landslide has a long-tongue shape. The landslide is about $500 \mathrm{~m}$ in width, $1205 \mathrm{~m}$ in length, $5.2 \times 10^{5} \mathrm{~m}^{2}$ in area, and $1.5 \times 10^{7} \mathrm{~m}^{3}$ in volume [14]. The landslide can be classified as a translational rockslide, following Cruden and Varnes [15]. The slope is located on the convex bank of the Qinggan River, and there are two free faces in the west side and the front of the slope (Figures 2 and 3). The dip angle of the slope ranged from $10^{\circ}$ to $15^{\circ}$ at the lower part and ranged from $25^{\circ}$ to $30^{\circ}$ at the middle-upper part. The shear outlet of the landslide is on the bank of the Qingan River, and its elevation is between 90 and $100 \mathrm{~m}$ (Figure 4).

The average thickness of sliding mass is about $25 \mathrm{~m}$, and the maximum thickness is about $50 \mathrm{~m}$. The sliding mass of the Qianjiangping landslide is mainly composed of blocky rock masses that are weathered from a highly to slightly weathered state. The blocky rock masses are comprised of silty mudstone, argillaceous siltstone, and feldspar quartzsandstone. The sliding surface of the landslide can be divided into two parts (Figure 4) [14]: the bedding section and the cutting-bed section. The bedding section located at the middle-upper part of the landslide is the interlayer staggered zone before sliding. The cutting-bed section located at the front of the landslide is a gently dipping discontinuous structural plane (including a set of gently dipping fractures and rock bridges). The two structural planes which formed the potential sliding surface controlled the stability of the slope. The bedrocks of the landslide are argillaceous siltstone, amaranth silty mudstone, and quartz sandstone of the lower Jurassic Niejiashan Formation $\left(J_{1-2 n}\right)$. And the bedrocks are fresh or slightly weathered. The groundwater table in the slope is very deep below the ground surface, and the groundwater recharge is mainly controlled by rainfall and the reservoir water level [6].

Figure 5 shows the reservoir impoundment process and rainfall process before the slope failure. From May 24 to June 10,2003 , the water level of the TGR rose from $80 \mathrm{~m}$ to $135 \mathrm{~m}$ at a steady rate and then maintained at a stable water level of $135 \mathrm{~m}$ until the slope failure. In addition, the accumulative rainfall reached $162.7 \mathrm{~mm}$ in the area within 22 days before the occurrence of the landslide.

Through detailed field investigation and geological exploration, scholars have done a detailed study on the geological conditions of the slope [14]. However, the influence degrees of reservoir impoundment and rainfall on the failure of the slope are still controversial, which needs to be further studied.

\section{Methodology}

3.1. Fluid-Solid Coupling Theory. In this paper, the Abaqus software, one of the most advanced and large generalpurpose FEM software, was employed to carry out the fluid-solid coupling analysis on groundwater movement and stress field of the slope under the influence of reservoir impoundment and rainfall. Based on porous medium theory, it is assumed that the fluid in the porous medium follows Darcy's law in the Abaqus software. Using Galerkin finite element scheme, the node displacement and pore water pressure are discretized as freedom degrees of node, and the mechanical balance equation and the seepage continuity equation are obtained. By coupling the two equations directly, the governing equation of fluid-solid coupling can be obtained:

$$
\begin{aligned}
{[\mathbf{K}]\{\Delta \bar{\delta}\}-[L]\{\Delta \bar{p}\} } & =\{F\}-\{I\}, \\
-[B]^{\mathrm{T}}\{\Delta \bar{\delta}\}-\Delta t[H]\{\Delta \bar{p}\} & =\{R\},
\end{aligned}
$$

where $[\mathbf{K}]$ is the stiffness matrix, $\{\Delta \bar{\delta}\}$ is the displacement increment, $[L]$ is the nodal force corresponding to the pore water pressure of the node, $\{\Delta \bar{p}\}$ is the increment of the pore water pressure, $\{F\}$ is the external load of the node, $\{I\}$ is the unbalanced force of the last incremental step in the incremental iteration process, $[B]$ is the change of fluid volume corresponding to node deformation, $[H]$ is the change of fluid volume corresponding to the change of pore water pressure, $\{R\}$ is the correction for the change of fluid volume, and $\Delta t$ is the time step. In the fluid-solid coupling process, (1) forms the basis of iterative solution in one time step. When displacement boundary conditions and seepage boundary conditions are satisfied and elements enter the plastic zone, it is only necessary to replace the elastic matrix with the elasticplastic matrix and perform a plastic iterative calculation.

3.2. Failure Approach Index. At present, the strength theory of rock under a complex stress state has developed rapidly, and there are many calculation methods for the stability of landslide [16-18]. These strength theories can well characterize the failure mechanism of rock mass and be helpful to analyze the range and evolution process of the damage zone, but they cannot quantitatively describe the potential dangerous level of the rock mass in the elastic region and the damage degree of the plastic zone [19]. In order to overcome these shortcomings, the failure approach index (FAI) was put forward on the basis of the yield approach index (YAI) [19]. The failure approach index is a quantitative index which can comprehensively evaluate the dangerous level of rock 


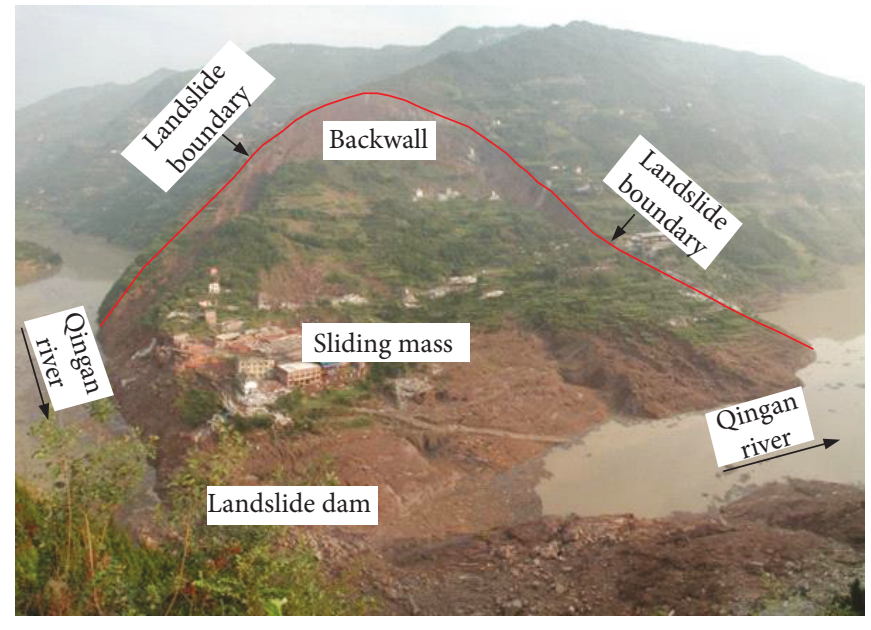

(a)

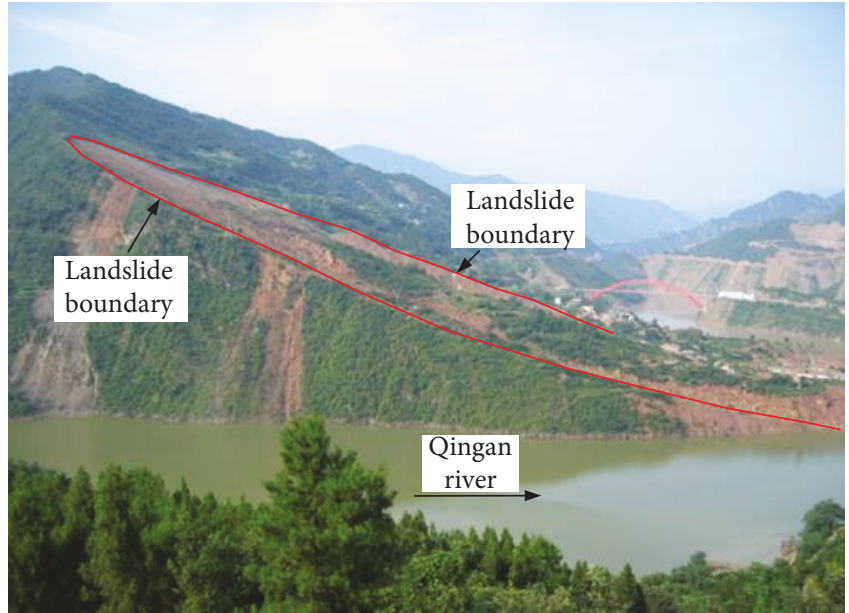

(b)

Figure 2: Photos of the Qianjiangping landslide [14]: (a) panorama of the landslide; (b) upstream side view of the landslide.
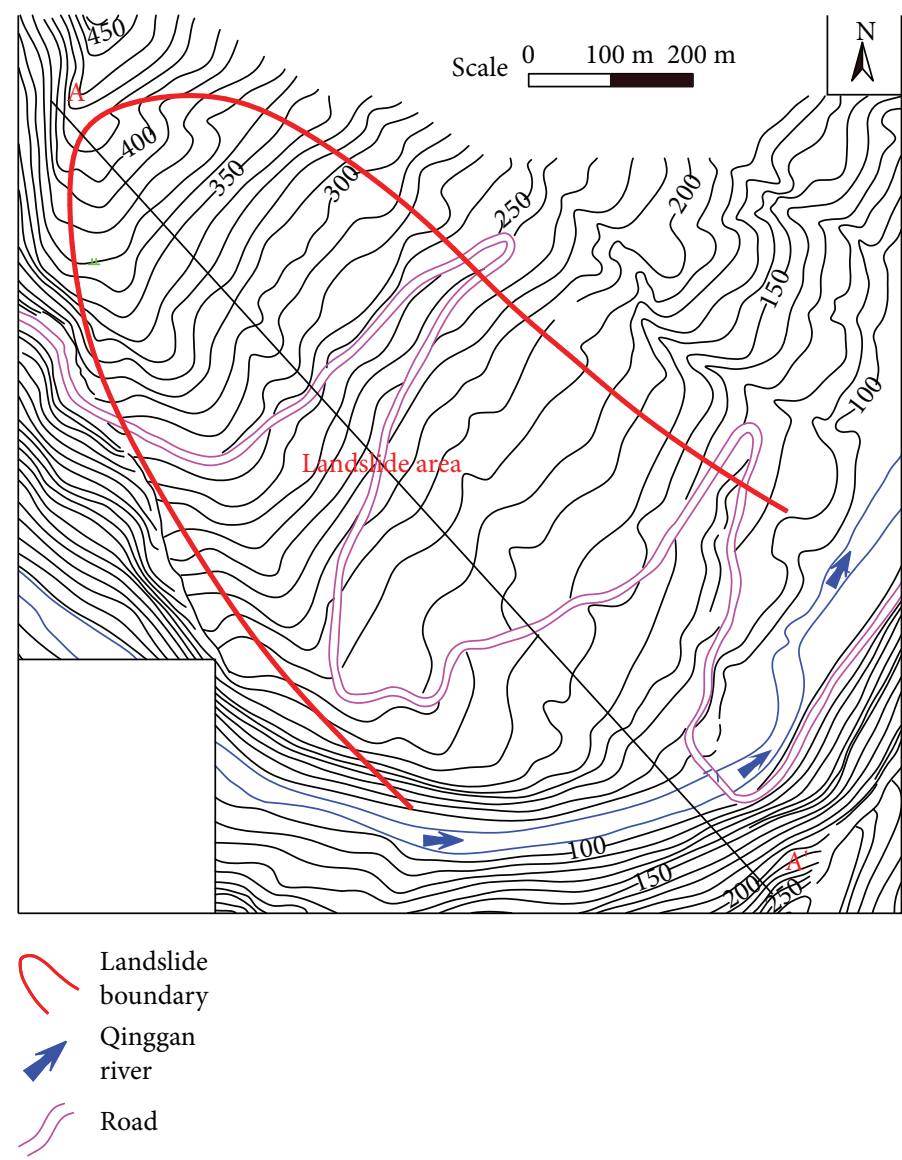

FIgURE 3: Topographical map of the Qianjiangping slope.

mass in the elastic region and the damage degree in the plastic zone. The formula of FAI is described as

$$
\mathrm{FAI}= \begin{cases}\omega, & 0 \leq \omega<1, \\ 1+\mathrm{FD}, & \omega=1, \mathrm{FD} \geq 0\end{cases}
$$

where $\omega$ is the phase complementary parameter of YAI ( $\omega=1-$ YAI $)$ and FD is the failure degree to evaluate the damage degree of the rock mass.

$$
\mathrm{FD}=\frac{\bar{\gamma}_{\mathrm{p}}}{\bar{\gamma}_{\mathrm{p}}^{\mathrm{r}}}
$$




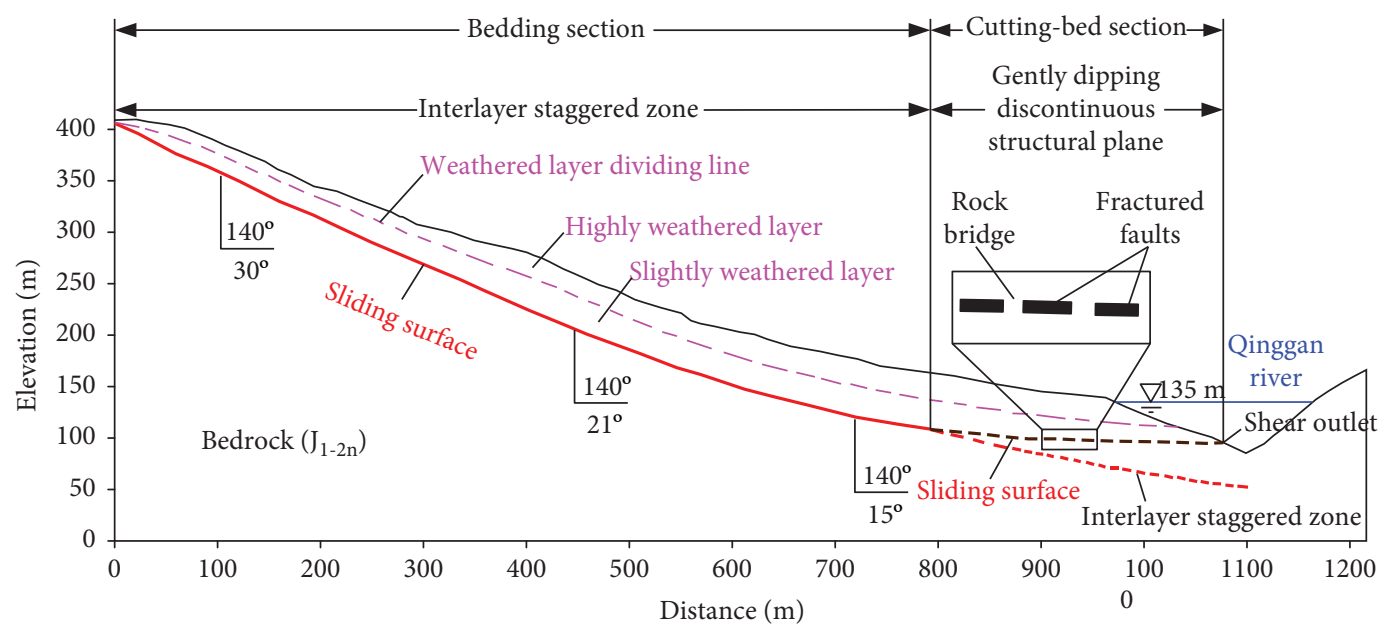

Figure 4: A-A' geological profile of the Qianjiangping slope [14].

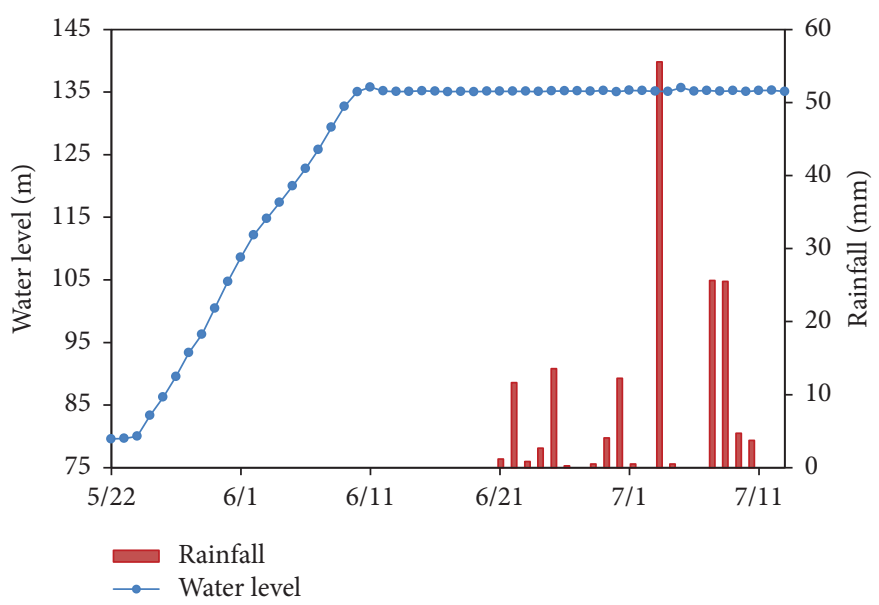

FIGURE 5: The impounding process of the TGR and the rainfall process in the slope region before the slope failure [6].

where $\bar{\gamma}_{\mathrm{p}}$ is the equivalent plastic shear strain and $\bar{\gamma}_{\mathrm{p}}^{\mathrm{r}}$ is the equivalent plastic shear strain limit corresponding to the initial point of the residue segment on the stress-strain curves. $\bar{\gamma}_{\mathrm{p}}$ is defined as

$$
\bar{\gamma}_{\mathrm{p}}=\sqrt{0.5 e_{i j}^{\mathrm{p}} e_{i j}^{\mathrm{p}}}
$$

where $e_{i j}^{\mathrm{p}}$ is the plastic deviator strain $\left(e_{i j}^{\mathrm{p}}=\varepsilon_{i j}^{\mathrm{p}}-\varepsilon_{m}^{\mathrm{p}} \delta_{i j}\right)$.

Generally, the rock mass in slopes is mostly under a relatively low stress state, and the yield failure of the rock mass conforms to the Mohr-Coulomb yield criterion. The expression of YAI based on the Mohr-Coulomb yield criterion can be derived as

$$
\mathrm{YAI}=\frac{(1 / 3) I_{1} \sin \varphi+\left(\cos \theta_{\sigma}-(1 / \sqrt{3}) \sin \theta_{\sigma} \sin \varphi\right) \sqrt{J_{2}}-c \cos \varphi}{(1 / 3) I_{1} \sin \varphi-c \cos \varphi},
$$

where $c$ and $\varphi$ denote the cohesion and the internal friction angle, respectively; $I_{1}$ is the first invariant of stress tensor; $J_{2}$ is the second invariant of deviatoric stress tensor; and $\theta_{\sigma}$ is the so-called Lode's angle. $I_{1}, J_{2}$, and $\theta_{\sigma}$ can be calculated by

$$
\begin{aligned}
I_{1} & =\sigma_{1}+\sigma_{2}+\sigma_{3}, \\
J_{2} & =\frac{1}{6}\left[\left(\sigma_{1}-\sigma_{2}\right)^{2}+\left(\sigma_{2}-\sigma_{3}\right)^{2}+\left(\sigma_{3}-\sigma_{1}\right)^{2}\right], \\
\theta_{\sigma} & =\arctan \left[\frac{2 \sigma_{2}-\sigma_{1}-\sigma_{3}}{\sqrt{3}\left(\sigma_{1}-\sigma_{3}\right)}\right],
\end{aligned}
$$

where $\sigma_{1}, \sigma_{2}$, and $\sigma_{3}$ are the maximum, intermediate, and minimum principal stress, respectively.

The FAI can quantitatively describe the dangerous degree of rock under a certain stress state. When $0 \leq \mathrm{FAI}<1.00$, the rock is in an elastic stage, and the greater the FAI value, the closer the rock mass is to the yielding state; if $1.00 \leq \mathrm{FAI}<2.00$, the rock is in a yielding state. When $\mathrm{F}$ $\mathrm{AI} \geq 2.00$, the rock is in a failure stage. In this paper, the FAI was employed to quantitatively express the dangerous degrees of rock in the slope under the influence of reservoir impoundment and rainfall. 


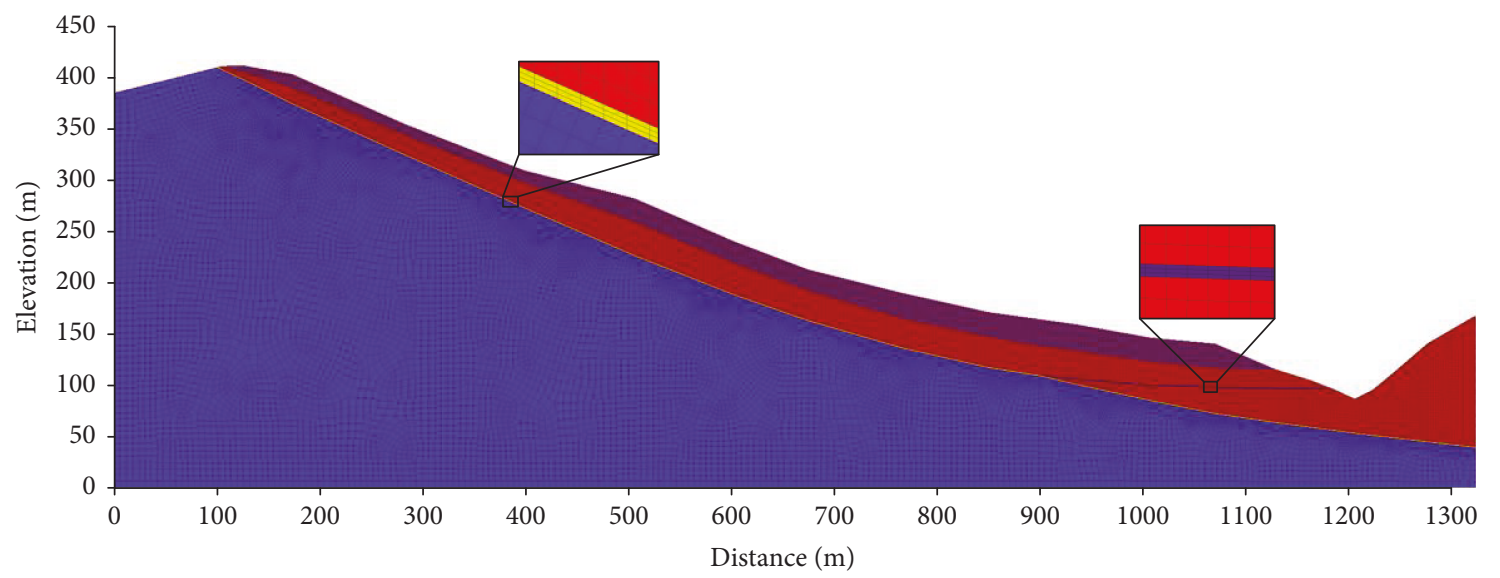

(1) Bedrock

(2) Interlayer staggered zone

(4) Slightly weathered layer

(3) Gently dipping discontinuous structural plane

(5) Highly weathered layer

FIGURE 6: Mesh model of the Qianjiangping slope.

TABle 1: Physical and mechanical parameters of material.

\begin{tabular}{|c|c|c|c|c|c|c|c|c|c|c|c|}
\hline \multirow[t]{2}{*}{ Material } & \multirow[t]{2}{*}{$\begin{array}{l}\text { Unit weight } \\
\gamma\left(\mathrm{kN} / \mathrm{m}^{3}\right)\end{array}$} & \multirow[t]{2}{*}{$\begin{array}{l}\text { Void } \\
\text { ratio } e\end{array}$} & \multirow[t]{2}{*}{$\begin{array}{c}\text { Saturated unit } \\
\text { weight } \\
\gamma\left(\mathrm{kN} / \mathrm{m}^{3}\right)\end{array}$} & \multicolumn{2}{|c|}{$\begin{array}{c}\text { Modulus of } \\
\text { elasticity } \\
E(\mathrm{MPa})\end{array}$} & \multirow[t]{2}{*}{$\begin{array}{l}\text { Poisson's } \\
\text { ratio } v\end{array}$} & \multicolumn{2}{|c|}{$\begin{array}{c}\text { Friction } \\
\text { angle } \\
\varphi\left(^{\circ}\right)\end{array}$} & \multicolumn{2}{|c|}{$\begin{array}{l}\text { Cohesion } \\
c(\mathrm{kPa})\end{array}$} & \multirow[t]{2}{*}{$\begin{array}{c}\text { Permeability } \\
\text { coefficient } \\
k(\mathrm{~m} / \mathrm{s})\end{array}$} \\
\hline & & & & A & B & & A & B & A & B & \\
\hline $\begin{array}{l}\text { Highly weathered } \\
\text { layer }\end{array}$ & 23.5 & 0.54 & 24.5 & 500 & 250 & 0.38 & 30 & 28 & 100 & 50 & $5 \times 10^{-5}$ \\
\hline $\begin{array}{l}\text { Slightly weathered } \\
\text { layer }\end{array}$ & 24.5 & 0.33 & 25.5 & 5000 & 2500 & 0.32 & 35 & 32 & 500 & 250 & $1 \times 10^{-5}$ \\
\hline $\begin{array}{l}\text { Gently dipping } \\
\text { discontinuous } \\
\text { structural plane }\end{array}$ & 23.5 & 0.55 & 24.5 & 1000 & 500 & 0.38 & 32 & 28 & 200 & 95 & $5 \times 10^{-5}$ \\
\hline $\begin{array}{l}\text { Interlayer } \\
\text { staggered zone }\end{array}$ & 16.3 & 0.43 & 23.2 & 50 & 25 & 0.40 & 12 & 10 & 18 & 15 & $4 \times 10^{-4}$ \\
\hline Bedrock & 25.0 & 0.11 & 26.0 & \multicolumn{2}{|c|}{20000} & 0.26 & & & \multicolumn{2}{|c|}{4000} & $3 \times 10^{-11}$ \\
\hline
\end{tabular}

\section{Numerical Simulation}

4.1. Finite Element Mesh Model and Boundary Conditions. Based on the A-A' geological profile of the Qianjiangping slope (Figure 4), a mesh model for numerical simulation by FEM was established (Figure 6). The model with a horizontal distance of $1320 \mathrm{~m}$ and a vertical height of $409 \mathrm{~m}$ is composed of 30,868 elements and 62,756 nodes. And the model is divided into five areas (Figure 6): the number 1 area is the bedrock, the number 2 area is the interlayer staggered zone, the number 3 area is the gently dipping discontinuous structural plane, the number 4 area is the slightly weathered layer, and the number 5 area is the highly weathered layer. The following boundary conditions are used for the calculation: the ground is free, normal constraints are applied to the sides of the slope, and the bottom boundary is fixed.

4.2. Constitutive Model and Yield Criterion. Under the conditions of reservoir impoundment and rainfall, rock mass in the slope is generally in an elastic or plastic or elastic- plastic state. The Drucker-Prager yield criterion and the Mohr-Coulomb yield criterion are commonly used to judge the yield state of rock mass of slopes. For the Qianjiangping slope, the rock mass in the shallow layer of the slope is in a low stress state. Under low confining pressure conditions, brittle failure of the rock occurs at the end of an elastic stage and bearing capacity of the rock is almost lost; at the same time, the yield failure of the rock conforms to the MohrCoulomb yield criterion. In addition, the Mohr-Coulomb yield criterion is widely used in slope engineering. Therefore, the ideal elastic-plastic model based on the Mohr-Coulomb yield criterion is adopted in this numerical simulation.

4.3. Physical and Mechanical Parameters of Material in the Slope. The physical and mechanical parameters of material in the slope determined by tests, engineering analogy, and parameter inversion analysis [14] are listed in Table 1.

4.4. Schemes of Calculated Conditions. In order to distinguish and quantize the influence degrees of reservoir 
TABLE 2: Schemes for numerical simulation.

\begin{tabular}{|c|c|c|}
\hline Scheme & Condition & Description \\
\hline 1 & Initial state & $\begin{array}{l}\text { The effects of reservoir impoundment and rainfall were not considered. The water } \\
\text { level of the Qinggan River was } 90 \mathrm{~m} \text {. The state expressed in this scheme was the } \\
\text { initial state of the slope before reservoir impoundment. }\end{array}$ \\
\hline 2 & Reservoir impoundment & $\begin{array}{l}\text { The water level of the Qinggan River rose from } 90 \text { to } 135 \mathrm{~m} \text { in } 15 \text { days } \\
\text { (May 27,2003-June 10,2003) with a rate of } 3 \mathrm{~m} \text { per day and maintained at a } \\
\text { constant value of } 135 \mathrm{~m} \text { for } 33 \text { days (June 10, 2003-July 13, 2003). In this scheme, } \\
\text { the interlayer staggered zone, the gently dipping discontinuous structural plane, } \\
\text { and the rock mass at the toe of the slope were submerged by the reservoir water } \\
\text { [10,13,14]; therefore, their physical and mechanical parameters below the } \\
\text { reservoir water level changed from the natural state to saturated state (values of } \\
\text { modulus of elasticity, friction angle, and cohesion changed from A column } \\
\text { to B column in Table } 1 \text { ) in this scheme. }\end{array}$ \\
\hline 3 & Rainfall & $\begin{array}{c}\text { The water level of the Qinggan River maintained at } 90 \text { m, and the rainfall } \\
\text { process lasted } 22 \text { days (June 22, 2003-July 13,2003, shown in Figure 5). } \\
\text { Because intermittent rainfall was difficult to make the rock mass saturated, } \\
\text { in this scheme, strength parameters of the rock mass were not weakened; } \\
\text { values of modulus of elasticity, friction angle, and cohesion were designated } \\
\text { as values in A column of Table } 1 .\end{array}$ \\
\hline 4 & Reservoir impoundment and rainfall & $\begin{array}{l}\text { This scheme was divided into two stages. At the first stage, from May } 27 \text { to } \\
\text { June } 10,2003 \text {, the water level rose from } 90 \text { to } 135 \mathrm{~m} \text { and then maintained } \\
\text { at } 135 \mathrm{~m} \text { to June } 21,2003 \text {. At the second stage, from June } 22,2003 \text {, to } \\
\text { July } 13,2003 \text {, the reservoir water level maintained at } 135 \mathrm{~m} \text {, and the } \\
\text { slope underwent the rainfall process (Figure 5). In this scheme, the toe } \\
\text { of the slope was affected by reservoir impoundment; the values of } \\
\text { modulus of elasticity, friction angle, and cohesion of the rock mass } \\
\text { changed from the natural state to saturated state the same as scheme } 2 \text {. }\end{array}$ \\
\hline
\end{tabular}

impoundment and rainfall on the failure of the slope, four schemes for numerical simulation were designed (Table 2).

4.5. Simulation Results. Based on fluid-solid coupling theory, the Abaqus software was employed to calculate the groundwater movement and stress distribution in the slope under the four above-mentioned schemes, and the groundwater tables and stress fields in the slope under each scheme were obtained.

4.5.1. Simulation Results of the Seepage Field. Figure 7 exhibits the changes in the groundwater tables in the slope under the four schemes.

The groundwater table in the Qianjiangping slope in scheme 1 is shown in Figure 7(a). Under the calculated conditions of this scheme, the groundwater table in the slope is almost horizontal and below the gently dipping discontinuous structural plane.

During the reservoir impoundment from May 27, 2003, to July 13, 2003, the dynamic changes of the groundwater tables are demonstrated in Figure 7(b). In scheme 2, the groundwater table rises continuously with the rising of reservoir water level. The gently dipping discontinuous structural plane and rock mass at the toe of the slope are gradually submerged in groundwater. Due to the huge difference of permeability coefficient between the interlayer staggered zone and the bedrock, the groundwater table appears to bend in S-shape near the interlayer staggered zone. From June 11, 2003 , to July 13,2003 , the reservoir water level is maintained at $135 \mathrm{~m}$, the groundwater table in the front of the slope basically do not rise any longer, and the reservoir water continues to permeate into the bedrock.

Variations in groundwater tables in scheme 3 are depicted in Figure 7(c). It can be seen that the groundwater tables of the slope change greatly during the course of rainfall. The groundwater table at the toe of the slope is horizontal at the beginning of rainfall. The heavy rainfall occurred on the 5th, 10th, 13th, and 18th day after it began to rain, and the highest groundwater tables in the rock mass above the potential sliding surface rise to $126.4 \mathrm{~m}, 122.7 \mathrm{~m}, 233.1 \mathrm{~m}$, and $169.3 \mathrm{~m}$, respectively. After each heavy rainfall, the groundwater in the slope discharges into the reservoir, and the groundwater tables quickly drop nearly to $90 \mathrm{~m}$ (such as on the 9th, 16th, and 22nd day after it began to rain).

Figure 7(d) displays the groundwater tables in the slope in scheme 4. At the first stage of this scheme (from May 27, 2003 , to June 21, 2003), the groundwater table is only affected by reservoir impoundment, and its change process is similar to that in scheme 2. And the groundwater level reaches $135 \mathrm{~m}$ at the end of the first stage. At the second stage of this scheme (from June 22, 2003, to July 13, 2003), the slope begins to undergo rainfall. When heavy rainfall occurred on the 5th, 10th, 13th, and 18th day after it began to rain, the highest point of groundwater level in the rock mass above the potential sliding surface rises to $151.5 \mathrm{~m}, 149.4 \mathrm{~m}, 243.4 \mathrm{~m}$, and $195.8 \mathrm{~m}$, respectively. After each heavy rainfall, the groundwater in the slope discharges into the reservoir the same as 

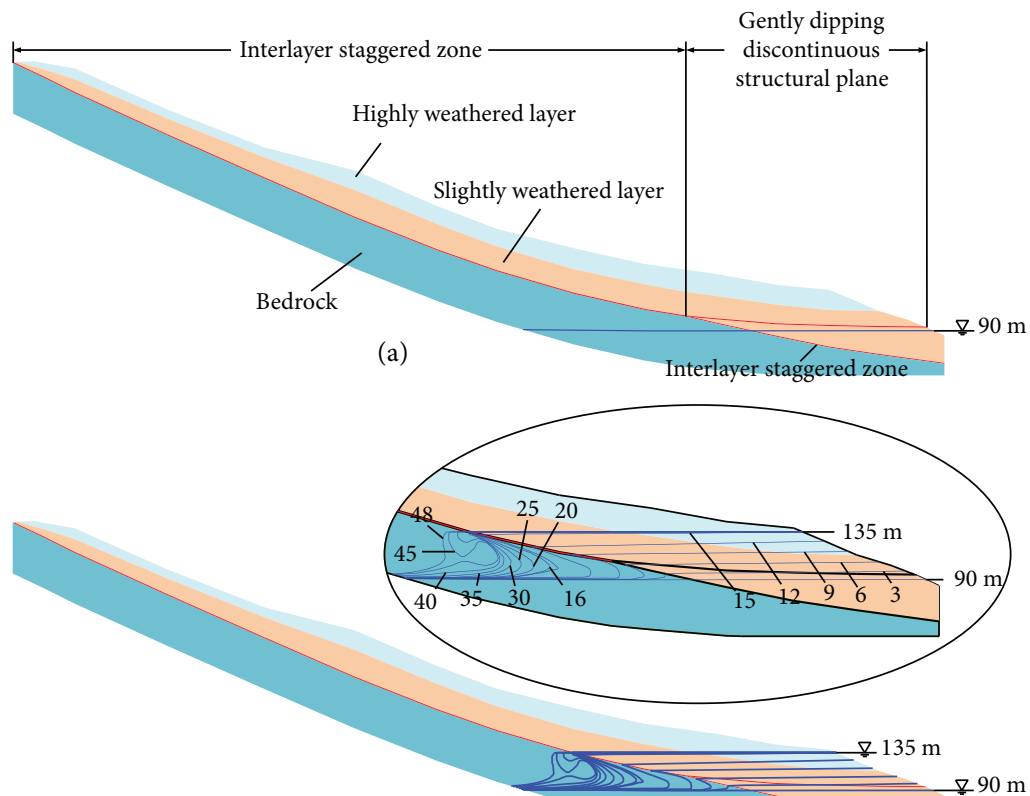

(b)

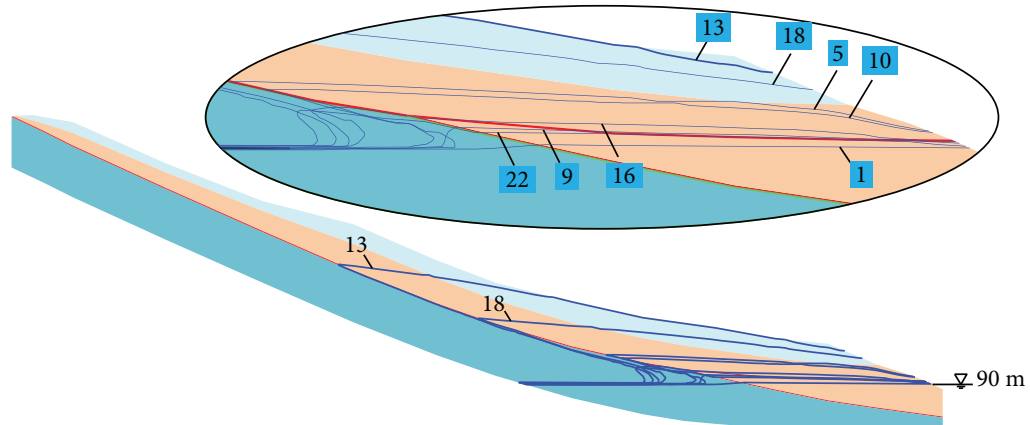

(c)

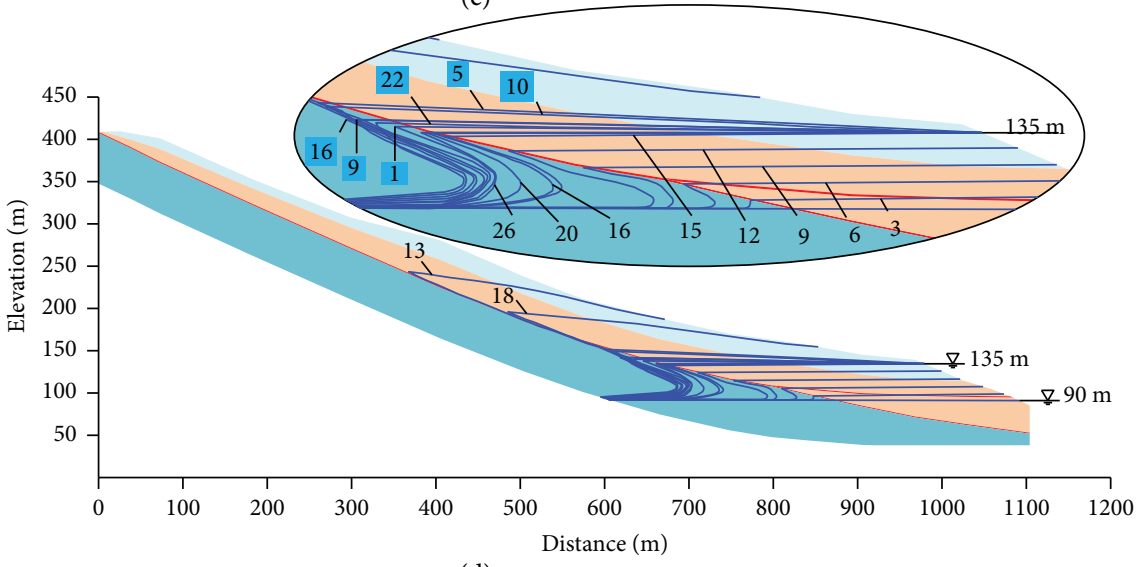

(d)

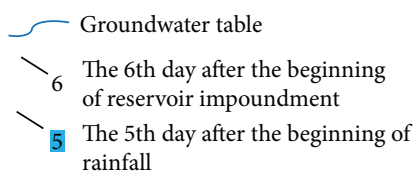

Figure 7: Groundwater tables in different schemes.

that in scheme 3, and the groundwater tables quickly drop nearly to $135 \mathrm{~m}$ (such as on the 9th, 16th, and 22nd day after it began to rain).
4.5.2. Simulation Results of FAI Distribution. Based on (2), (3), (4), (5), (6), (7), and (8), the computational program used to calculate FAI values is developed. Calculation results of 


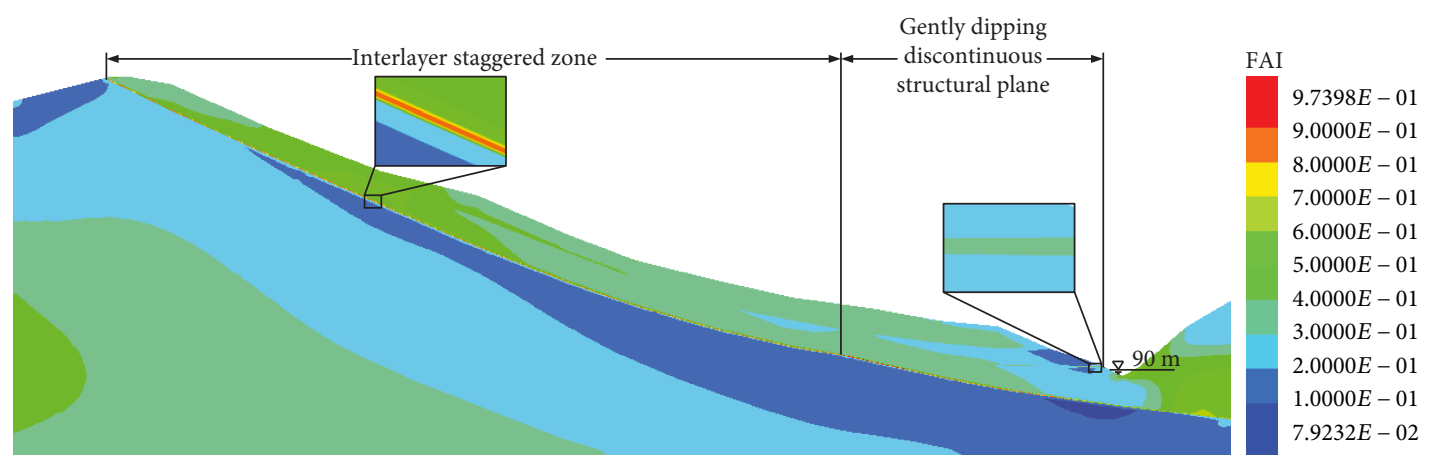

(a)

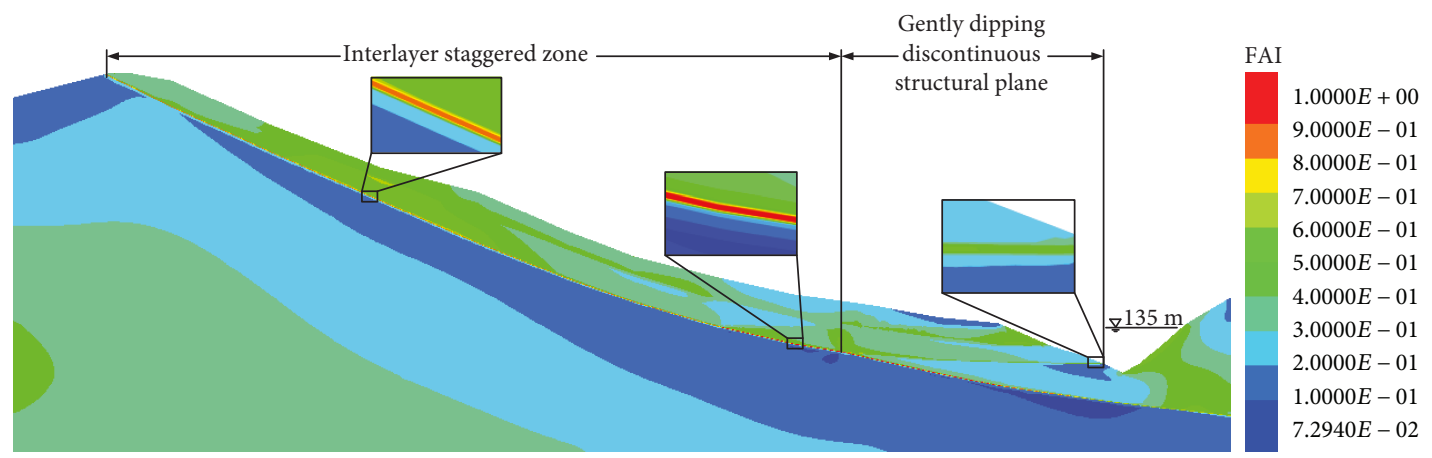

(b)

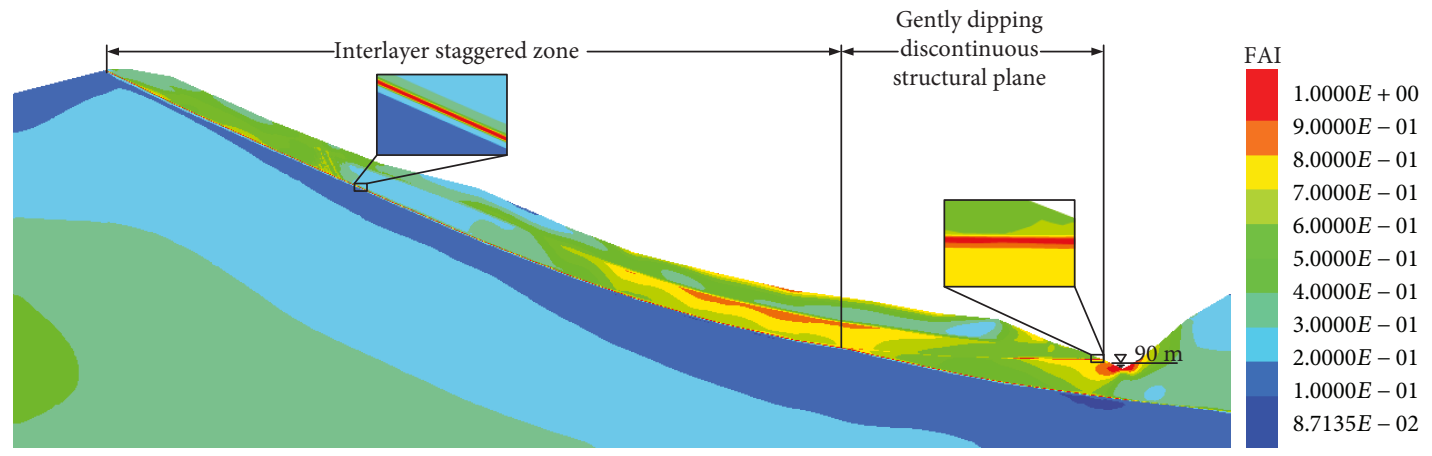

(c)

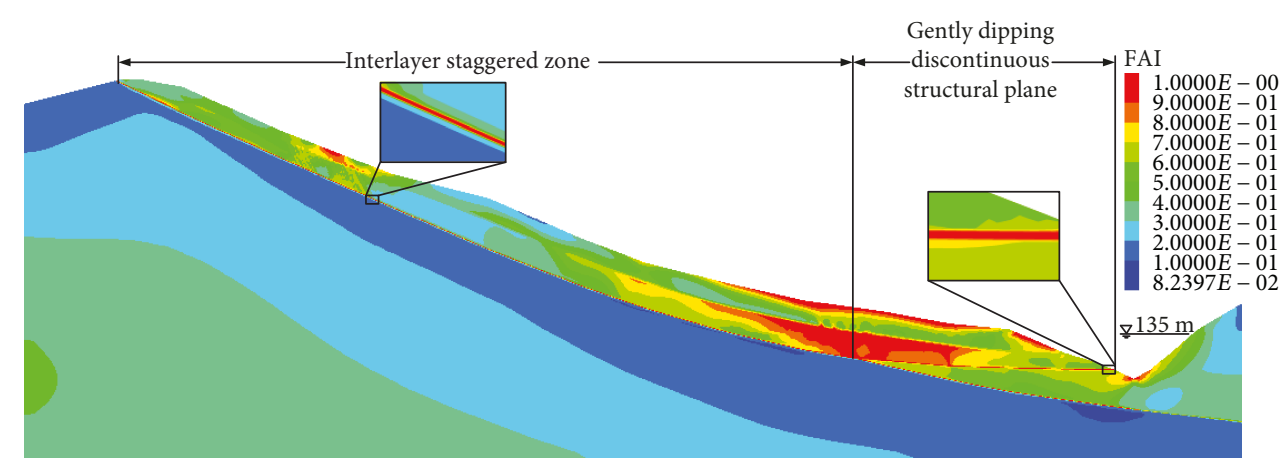

$\overline{100 \mathrm{~m}}$

(d)

FIgURE 8: The FAI distributions of each scheme. 
stress fields in each scheme were put into the computational program, and the FAI distributions of each scheme can be obtained (Figure 8).

The FAI distribution of scheme 1 is shown in Figure 8(a). In this scheme, FAI values of every point in the slope are less than 1.00, which indicates that the rock mass of the slope does not yield and the slope is in a safe state. The ranges of FAI values of the interlayer staggered zone and the gently dipping discontinuous structural plane are $0.81 \sim 0.85$ and $0.25 \sim 0.40$, respectively. FAI values of the rock mass above the potential sliding surface range from 0.12 to 0.52 , and the relatively high FAI values appear in the upper part of the slope.

The FAI distribution of the slope under the condition of reservoir impoundment is demonstrated in Figure 8(b). In this scheme, FAI values of the interlayer staggered zone below the reservoir water level of $135 \mathrm{~m}$ reach 1.00 , which shows that the rock mass in this region has been in a yielding state. FAI values of the interlayer staggered zone above $135 \mathrm{~m}$ are between 0.82 and 0.86 and have almost no change compared with those in scheme 1 . FAI values of the gently dipping discontinuous structural plane are $0.32 \sim 0.67$, the FAI values at both ends are greater than those in the middle section, and the maximum value is 0.27 bigger than that in scheme 1 . FAI values of the rock mass above the potential sliding surface range from 0.11 to 0.64 , and the distribution range of relatively high FAI values is greater than that in scheme 1.

The FAI distribution of the slope in scheme 3 is displayed in Figure 8(c). In this scheme, FAI values of the whole interlayer staggered zone are equal to 1.00 , which means that the interlayer staggered zone as a whole is in a yielding state. FAI values of the gently dipping discontinuous structural plane range from 0.48 to 0.98 , and the maximum value is 0.58 bigger than that in scheme 1. FAI values of the gently dipping discontinuous structural plane are low in the middle and high at both ends. The FAI value range of the rock mass above the potential sliding surface are $0.18 \sim 0.90$, and the distribution range of the relatively high FAI values is further enlarged compared with that in scheme 2. In addition, FAI values of the rock mass at the bottom of the river valley are 1.00 and are much greater than those in scheme 1 and scheme 2.

Figure $8(\mathrm{~d})$ exhibits the FAI distribution of the slope under the conditions of reservoir impoundment and rainfall. In this scheme, FAI values of the interlayer staggered zone and the gently dipping discontinuous structural plane are equal to 1.00, and the two structural planes are in a yielding state. FAI values of the rock mass near the junction of the interlayer staggered zone and the gently dipping discontinuous structural plane are greater than 0.90 , and the maximum value reaches 1.00 .

\section{Discussion}

The failure approach index (FAI) is an estimation index proposed by Zhang et al. [19] for evaluating the safety of surrounding rock in underground engineering. The index can quantitatively describe the stress-induced yield approaching

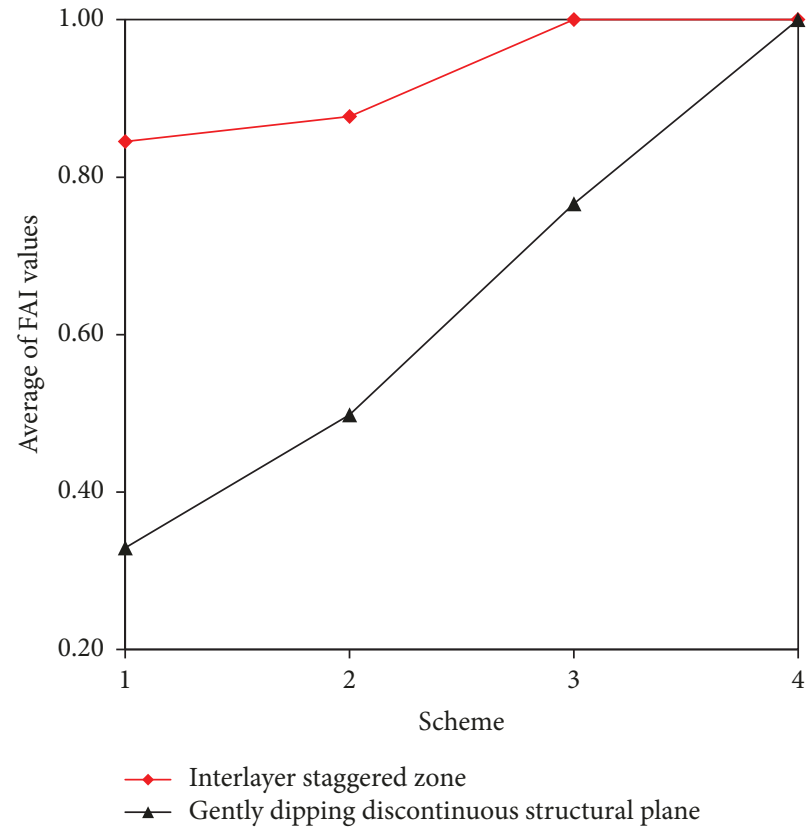

FIGURE 9: The average of FAI values of the potential sliding surface in each scheme.

risk in the elastic region and the damage degree during plastic flow [19]. FAI has been successfully applied in the stability assessment of surrounding rock during excavation, and its rationality and practicability have been verified [19-22]. Similar to underground engineering during excavation, slope engineering is always in the elastic or plastic state under loads. Thus, FAI can be employed to describe the yield risk of rock mass of the bank slope under the conditions of reservoir impoundment, rainfall, and combined effect of reservoir impoundment and rainfall. According to the above analysis, the influence degrees of the three conditions (reservoir impoundment, rainfall, and combined effect of reservoir impoundment and rainfall) on the failure of the Qianjiangping slope are quantified by FAI.

In order to further quantify the influence of reservoir impoundment and rainfall on the stability of the slope, the average of FAI values and the area formed by points whose FAI values are equal to 1.00 are calculated along the potential sliding surface of the slope (Figures 9 and 10). As shown in Figure 9, the averages of FAI values of the interlayer staggered zone and the gently dipping discontinuous structural plane in scheme 3 are both greater than those in scheme 2 , which suggests that the potential sliding surface is easier to yield under the influence of rainfall than under the individual effect of reservoir impoundment. Figure 10 shows that the area formed by points whose FAI values are equal to 1.00 in the potential sliding surface in scheme 3 is greater than that in scheme 2 , and the ratios of the plastic zone (which refer to the ratio of the area of the potential sliding surface in a yielding state to the total area of the potential sliding surface) in the potential sliding surface are $12 \%$ and $74 \%$ in scheme 2 and scheme 3, respectively, which means that the failure risk of the slope under the 


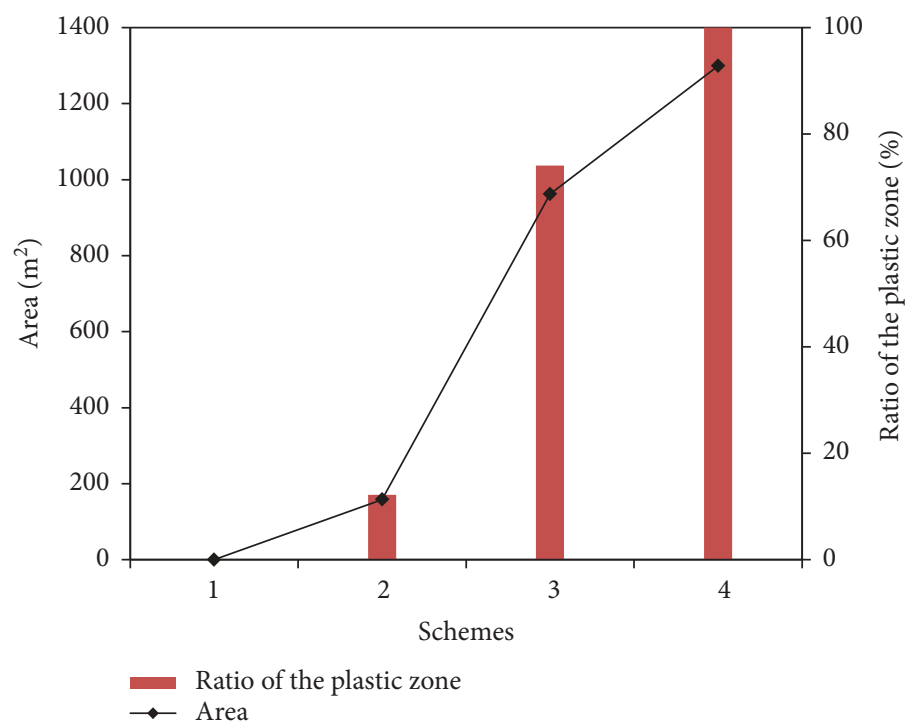

FIgURE 10: The area of the plastic zone in the potential sliding surface and the ratio of the plastic zone in each scheme.

condition of rainfall is greater than that under the condition of reservoir impoundment. Therefore, the influence degree of rainfall on the stability of the slope is greater than that of reservoir impoundment. In scheme 4 , the ratio of the plastic zone in the potential sliding surface reaches $100 \%$ (the area is equal to $1298 \mathrm{~m}^{2}$ ), and the FAI values of all points in the potential sliding surface are equal to 1.00. The comprehensive analysis on Figures 9 and 10 indicates that neither of the two factors (reservoir impoundment and rainfall) can trigger the failure of the slope alone, and the failure of the slope is caused by the combined effect of the two factors.

Calculating results of scheme 4 demonstrates that at the first stage of the scheme (from May 27 to June 10, 2003, the water level rose from 90 to $135 \mathrm{~m}$ and then maintained at $135 \mathrm{~m}$ to June 21 ), the reservoir water infiltration causes the continuous rise of the groundwater table at the toe of the slope, and the gently dipping discontinuous structural plane is immersed in groundwater on the 6th day after the beginning of reservoir impoundment (Figure $7(d)$ ). Rock mass at the toe of the slope is weakened by the reservoir water, which is very detrimental to the stability of the slope. At this moment, FAI values of rock mass in the potential sliding surface have increased compared with those before reservoir impoundment; to be specific, the average of the FAI values of the interlayer staggered zone increases from 0.85 to 0.88 and the average of FAI values of the gently dipping discontinuous structural plane increases from 0.33 to 0.50 (Figure 9). The slope is still stable at the first stage. At the second stage, rainfall infiltrated rapidly into the slope along the interlayer staggered zone and connected with the groundwater at the front of the slope. The groundwater table above the potential sliding surface is rapidly uplifted (Figure $7(d)$ ). At this stage, the rising of the groundwater table enhanced the unit weight of the rock mass above the potential sliding surface; at the same time, the rainfall infiltration increases the seepage force in the slope, which brings about the increase in the sliding force in the slope. The FAI value of every point in the potential sliding surface reached 1.00 (Figure 9); that is to say, the potential sliding surface yielded. At the end of the second stage, a penetrating sliding surface was formed along the potential sliding surface and the slope failure happened.

\section{Conclusions}

Based on the numerical simulation results and discussion mentioned above, some conclusions can be drawn as follows:

(1) The groundwater table in the lower part of the slope rises with the increase in the reservoir water level. Under the condition of heavy rainfall, the groundwater table in the middle-lower part of the slope rises rapidly. After each heavy rainfall, the groundwater will rapidly discharge to the reservoir, and the groundwater table drops nearly to the reservoir water level.

(2) The FAI distributions demonstrate that the reservoir impoundment changes the stress state in the low part of the slope much more than in the middle-upper part of the slope, and rainfall greatly increases the sliding force of the slope. Both reservoir impoundment and rainfall increase the risk of slope failure.

(3) The influence degree of rainfall on the stability of the Qianjiangping slope is greater than that of the reservoir impoundment, but neither of the reservoir impoundment and rainfall can trigger the failure of the Qianjiangping slope alone.

(4) The Qianjiangping landslide is caused by the combined effect of reservoir impoundment and rainfall. The strength of the rock bridges in the gently dipping 
discontinuous structural plane was weakened by the reservoir water due to water-rock interaction, which decreases the antisliding force of the slope. The rainfall increased the sliding force of the rock mass above the interlayer staggered zone of the slope, which led to obvious stress concentration at the lower part of the slope. Finally, the rock bridges around the gently dipping discontinuous structural plane fractured, and the slope slid.

\section{Conflicts of Interest}

The authors declare that they have no conflicts of interest.

\section{References}

[1] F. Wang, Y. Zhang, Z. Huo, X. Peng, S. Wang, and S. Yamasaki, "Mechanism for the rapid motion of the Qianjiangping landslide during reactivation by the first impoundment of the Three Gorges Dam reservoir, China," Landslides, vol. 5, no. 4, pp. 379-386, 2008.

[2] K. Yin, Y. Liu, and Y. Wang, "Physical model experiments of landslide-induced surge in Three Gorges Reservoir," Earth Science, vol. 37, no. 5, pp. 1067-1074, 2012.

[3] F.-W. Wang, Y. M. Zhang, Z. T. Huo, T. Matsumoto, and B. L. Huang, "The July 14, 2003 Qianjiangping landslide, Three Gorges Reservoir, China," Landslides, vol. 1, no. 2, pp. 157162, 2004.

[4] F. C. Dai, J. H. Deng, L. G. Tham, K. T. Law, and C. F. Lee, “A large landslide in Zigui County, Three Gorges area," Canadian Geotechnical Journal, vol. 41, no. 6, pp. 1233-1240, 2004.

[5] Q. Jiang, Z. Zhang, and W. Wei, "Research on triggering mechanism and kinematic process of Qianjiangping landslide," Disaster Advances, vol. 5, no. 4, pp. 631-636, 2012.

[6] W. Jian, Q. Xu, H. Yang, and F. Wang, "Mechanism and failure process of Qianjiangping landslide in the Three Gorges Reservoir, China," Environmental Earth Sciences, vol. 72, no. 8, pp. 2999-3013, 2014.

[7] H. Tang, R. Yong, and M. A. M. Ez Eldin, "Stability analysis of stratified rock slopes with spatially variable strength parameters: the case of Qianjiangping landslide," Bulletin of Engineering Geology and the Environment, vol. 76, no. 3, pp. 839-853, 2017.

[8] Z. Wang and R. Yang, "The activity characteristics and movement style of Qianjiangping landslide in the Three Gorges Reservoir region," The Chinese Journal of Geological Hazard and Control, vol. 16, no. 3, pp. 5-11, 2005.

[9] B. Wen, J. Shen, and J. Tan, "The influence of water on the occurrence of Qianjiangping landslide," Hydrogeology \& Engineering Geology, vol. 34, no. 3, pp. 12-18, 2008.

[10] S. Xiao, D. Liu, F. Jiang, and X. Jiang, "Geomechanical model experiment on Qianjiangping landslide in Three Gorges Reservoir area," Chinese Journal of Rock Mechanics and Engineering, vol. 29, no. 5, pp. 1023-1030, 2010.

[11] Q. Liao, X. LI, S. LI, and Y. Dong, "Occurrence, geology and geomorphy characteristics and origin of Qianjiangping landslide in Three Gorges Reservoir area and study on ancient landslide criterion," Chinese Journal of Rock Mechanics and Engineering, vol. 24, no. 17, pp. 3146-3153, 2005.

[12] Headquarters of Geological Hazard Control in Area of the Three Gorges Reservoir, "The Qianjiangping Landslide in
Shazhenxi town Zigui county Hubei province," The Chinese Journal of Geological Hazard and Control, vol. 14, no. 3, p. 142, 2003.

[13] L. Cao and X. Luo, "Experimental study of dry-wet circulation of Qianjiangping landslide's unsaturated soil," Rock and Soil Mechanics, vol. 28, pp. 93-97, 2007.

[14] S. Xiao, S. Wang, and Z. Hu, Research Report on Geomechanical Model of Qianjiangping Landslide, Three Gorges University, The Chinese Journal of Geological Hazard and Control, Yichang, China, 2007.

[15] D. Cruden and D. Varnes, "Landslide types and processes," Landslides-Investigation and Mitigation, vol. 247, pp. 36-75, 1996.

[16] Q. Jiang and C. Zhou, "A rigorous method for threedimensional asymmetrical slope stability analysis," Canadian Geotechnical Journal, vol. 55, no. 4, pp. 495-513, 2018.

[17] Q. Jiang and C. Zhou, "A rigorous solution for the stability of polyhedral rock blocks," Computers and Geotechnics, vol. 90, pp. 190-201, 2017.

[18] Y. Tang, Q. Jiang, and C. Zhou, "Approximate analytical solution to the Boussinesq equation with a sloping waterland boundary," Water Resources Research, vol. 52, no. 4, pp. 2529-2550, 2016.

[19] C. Q. Zhang, H. Zhou, and X. T. Feng, "An index for estimating the stability of brittle surrounding rock mass: FAI and its engineering application," Rock Mechanics and Rock Engineering, vol. 44, no. 4, pp. 401-414, 2011.

[20] C. Zhang, X. Feng, H. Zhou, S. Qiu, and W. Wu, “A top pilot tunnel preconditioning method for the prevention of extremely intense rockbursts in deep tunnels excavated by TBMs," Rock Mechanics and Rock Engineering, vol. 45, no. 3, pp. 289-309, 2012.

[21] C. Zhang, X.-T. Feng, H. Zhou, S. Qiu, and W. Wu, "Rockmass damage development following two extremely intense rockbursts in deep tunnels at Jinping II hydropower station, southwestern China," Bulletin of Engineering Geology and the Environment, vol. 72, no. 2, pp. 237-247, 2013.

[22] C. Zhang, X.-T. Feng, H. Zhou, S. Qiu, and Y. Yang, "Rock mass damage induced by rockbursts occurring on tunnel floors: a case study of two tunnels at the Jinping II hydropower station," Environmental Earth Sciences, vol. 71, no. 1, pp. 441-450, 2014. 

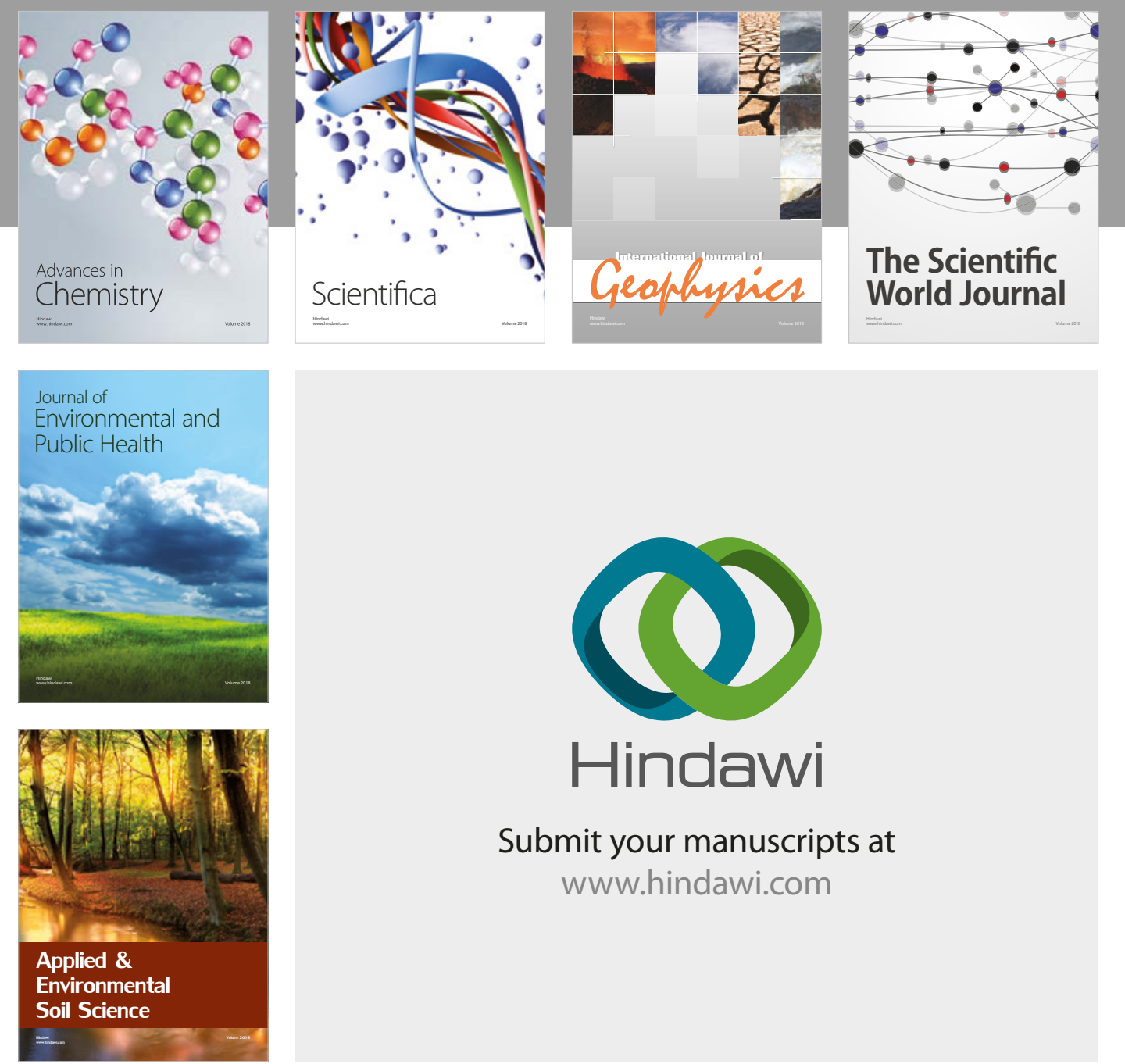

The Scientific

\section{World Journal}
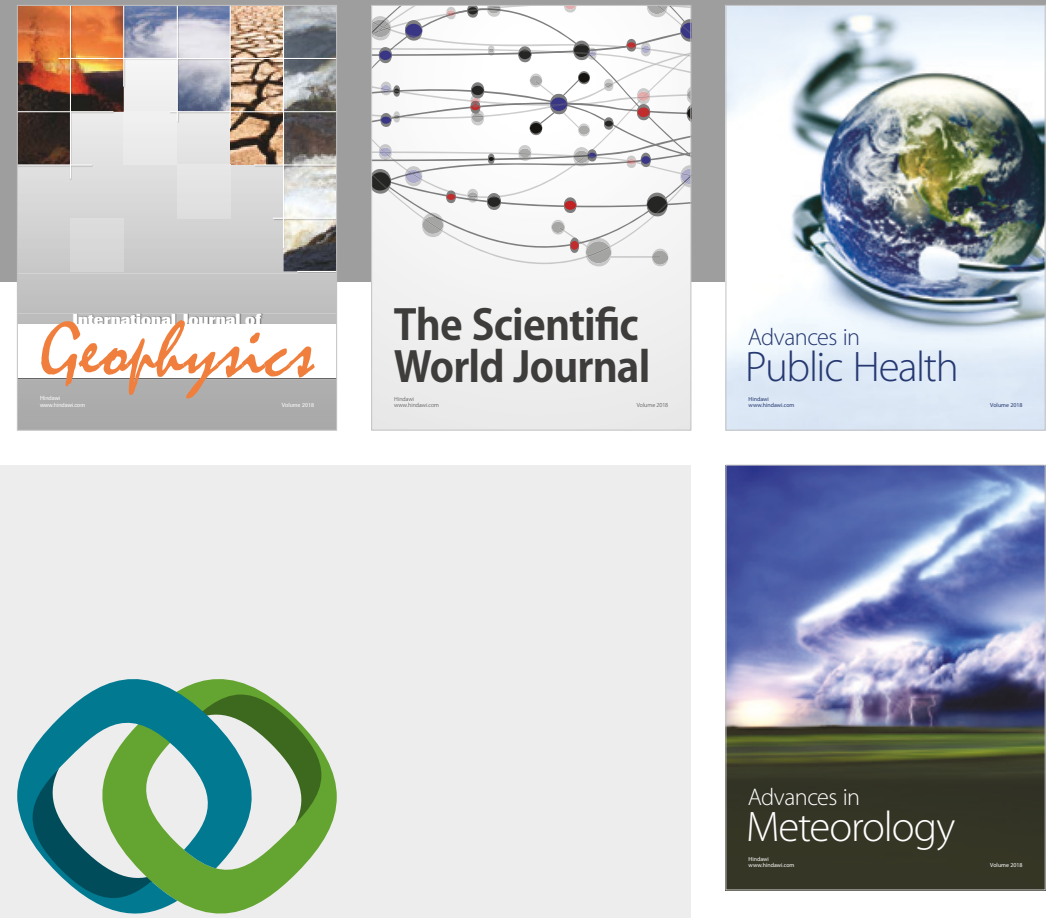

Advan

Public Health

\section{Hindawi}

Submit your manuscripts at

www.hindawi.com
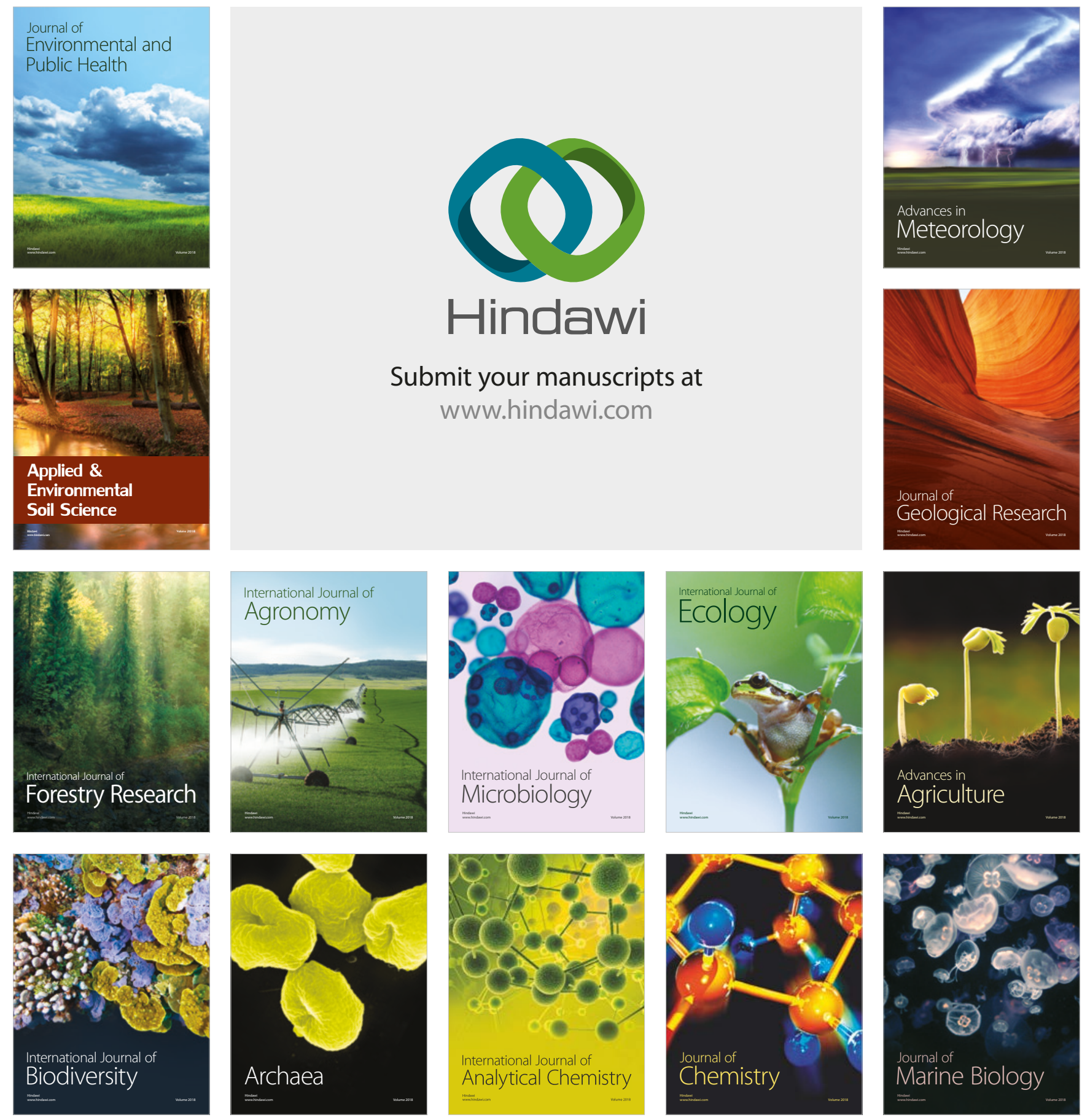